\title{
Fine Structure of the Auricular Muscle Cells in the Snail Euhadra senckenbergiana notoensis
}

\author{
By \\ MinoRU MIDSUKAMI \\ Anatomy Laboratory, The School of Allied Medical Professions, \\ Kanazawa University, Kanazawa 920, Japan \\ - Received for Publication, December 10, 1981-
}

\begin{abstract}
Key words: Cardiac muscle cells, Intercalated disc, Myofibrils, Pulmonate mollusc, Electron microscopy.

Summary : The auricular muscle cells of the land snail Euhadra senckenbergiana notoensis were studied. The nuclei were situated at all depths within the cells. In the myofibrils, A- and I-bands were seen. The diameters of the thick and thin filaments were approximately $32 \mathrm{~nm}$ and $6 \mathrm{~nm}$, respectively. The ratio between the thick and thin filaments was about 1 to 11 .

The Z-body was composed of only three or four thick filaments and was fragmentary in nature. Even when such fragments were lined up transversely, they not appear to have a basic cross-striated nature. The sarcotubular system was moderately developed. Attachment plaques and hemidesmosomes were found scattered over the whole plasma membrane. Intercalated discs were often observed. They consisted of interfibrillar junctions, desmosomes, nexal areas and unspecialized regions. The organization of the pulmonate cardiac muscle cells is discussed and comparep with that described for other species.
\end{abstract}

Fine structural studies on pulmonate cardiac muscle cells have been carried out in the garden snail Helix aspersa (North, 1963), in the agate snail Achatina fulica and closely related species Archachatina marginata (Baxter and Nisbet, 1963; Nisbet and Plummer, 1966, 1968, 1969), in the land snail Euhadra hickonis (Kawaguti, 1963b), and in the pond snail Lymnaea stagnalis (Plesch, 1977). However, most of these studies dealt with the ventricular muscle cells, and particularly with the contractile elements. Less is known about the cellular contact between the apposed muscle cells and the myofibrillar relation at this site in pulmonates. In contrast, the cardiac muscle cells of the cephalopod Sepia officinalis have been shown to consist of a well developed sarcotubular system (Schipp and Schäfer, 1969). Jensen and $\mathrm{T} j \phi$ nneland (1977), studying the heart muscle of the cephalopod Rossia macrosoma, have further demonstrated intercalated discs and desmosomes. The present study was designed to obtain more precise information on the fine structure of the cardiac muscle cells of pulmonate molluscs. 


\section{Material and Methods}

Fresh specimens of the bradyaenid land snail Euhadra senckenbergiana notoensis (shell height $20-25 \mathrm{~mm}$ ) were obtained locally. To prepare the cardiac tissue for study, the shell of the cardiac region was removed by cutting it off along the suture of the body whorl. The beating heart was then carefully dissected free and bathed in physiological saline solution (for detailed formulae, see Midsukami, 1979). The heart was immersed in a solution of $2.5 \%$ glutaraldehyde, consisting of sodium cacodylate buffer ( $\mathrm{pH}$ 7.4) and sucrose, for about $20 \mathrm{~min}$ at room temperature. Pieces of the auricle were excised promptly and immersed in a fresh fixative for an additional $20 \mathrm{~min}$ at $4^{\circ} \mathrm{C}$. They were then rinsed in a cold solution ( $\mathrm{pH} 7.4$ ) of sodium cacodylate and sucrose, and washed with the same cold buffer for a total of $60 \mathrm{~min}$. The pieces were post-fixed in a solution of $1 \%$ osmium tetroxide, consisting of sodium cacodylate buffer ( $\mathrm{pH}$ 7.4) and sucrose, for $60 \mathrm{~min}$ at $4^{\circ} \mathrm{C}$. They were then dehydrated in ethanol and propylene oxide, and embedded in Epon 812. Thin sections, cut with an LKB ultramicrotome, were stained with uranyl acetate and lead citrate, and examined under a Hitachi HU-12 or H-500 electron microscope.

The best results were obtained when the osmolarity of the fixatives was adjusted to 240-250 mOsm. These solutions were prepared from adequate amounts of sodium cacodylate and sucrose by measuring the osmotic pressure with an osmometer (Knauer, Berlin).

\section{Results}

The heart of Euhadra senckenbergiana notoensis was a simple two-chambered organ, comprising a thin-walled auricle and a thick-walled ventricle, and was wholly enclosed within the cavity defined by the translucent pericardium.

In the auricle, the myocardial layer was separated from the single layered epicardium by a distinct layer of connective tissue (Fig. 1). Towards the pericardial cavity, the epicardial cells had a brush border of microvilli about $0.6 \mu \mathrm{m}$ long, while the basal plasma membrane formed many deep invaginations. The apposed plasma membranes of these neighboring cells were equally separated from each other by a narrow intercellular space of only $15 \mathrm{~nm}$, and were seen to form complex folds over most of the contact area. A desmosome, such as the terminal bar often observed in the epithelial cells of the vertebrate intestine, usnally occurred at the apical ends of adjacent cells. The epicardial cells were lined with a thin basement membrane and a thick amorphous layer. The latter was about $1.6 \mu \mathrm{m}$ thick, but often varied in thickness from about $0.2 \mu \mathrm{m}$ to $3.0 \mu \mathrm{m}$ or more. This layer consisted of a finely woven reticular framework, in which numerous collagen fibrils were present. Connective tissue cells of various shapes, a few nerve cords and small muscle cells made up the layer of connective tissue. The myocardium consisted of an irregular, anastomosing network, which lay in the cardiac lumen and was, therefore, bathed with the hemolymph circulating through the heart.

The myocardial layer was characterized by a high density of muscle cells, with little extracellular space, and a regular surface contour. These cells were closely arranged just like elaborate stonework. They had an oval or round shape in crosssection, being 10 to $14 \mu \mathrm{m}$ in diameter at their thickest part (Fig. 3), and a fusiform shape in longitudinal section, being about $25 \mu \mathrm{m}$ in length. They were invested with a sarcolemma consisting of an outer diffuse layer of basement membrane and 
an inner plasma membrane. The latter, however, revealed spcializations of structure in the abutting sites of adjacent muscle cells and in the attachment areas of myofibrils.

The nuclei were from 7 to $13 \mu \mathrm{m}$ in diameter and round or fusiform in shape, occurring at all depths within the cells. In the nuclei, the chromatin was moderately condensed and formed thin bands around the periphery of the nucleus. $\mathrm{Nu}$ cleoli were also seen in some nuclei. The Golgi complexes and multivesicular bodies were frequently found in close proximity to the nuclei (Fig. 2). Glycogen particles were scattered throughout the sarcoplasm, but were most concentrated around the mitochondria in the perinuclear area.

Mitochondria were very abundant in this muscle. In cross-section, they were seen to form dense aggregations in the central region of the cell (Fig 3). In longitudinal section, they could be seen lined up in rows between the myofibrils. Such mitochondria were characterized by their numerous cristae and the marked electron density of the matrix. Mitochondria containing small dense granules such as those often found in certain crustacean cardiac muscle cells (Midsukami, 1981), were observed in the present specimens.

The myofibrils of the snail auricular muscle were similar in appearance to those seen in the striated muscles of other animals. The usual two-unit interdigitation system of myofilaments was clearly visible. However, the sarcomeric organization was of a very simple kind. The knob of the sarcomere did not appear as a usual transverse Z-line, but instead took the form of a small ellipsoidal body, "Z-body", its long axis being aligned with that of the myofibril. The Z-body was composed of aggregated thin filaments which were embedded in a matrix of dense, amorphous material. These bodies measured 500 to $600 \mathrm{~nm}$ in length and 80 to $100 \mathrm{~nm}$ width. The small size of the Z-body unit limited the width of the myofibril. In oblique sections, one Z-body appeared to be associated with only 3 to 4 thick filaments, while in cross-sections the ratio between thick and thin filaments was about 1 to 11 . This indicated that one $Z$-body comprised roughly 30 to 40 thin filaments. The thick filaments were confined to the A-band, whereas the thin filaments occupied the I-band, interdigitating with thick ones of the A-band. The thick filaments sometimes appeared to occupy the whole length of the sarcomere. The thick and thin filaments measured approximately $32 \mathrm{~nm}$ and $6 \mathrm{~nm}$ in diameter, respectively. One sarcomere unit averaged 2.6 to $3.9 \mu \mathrm{m}$ in length, but even within the same cell the myofibrils were differently oriented and the thick filaments may vary in length.

The Z-bodies were not always quite precisely arranged in a row at right angles to the long axis of the cell, and were, moreover, fragmentary in nature. Even when such fragments were lined up transversely, they did not appear to have a basic cross-striated nature; in other words, the myofibrils of the snail heart are composed of perforated and discontinuous Z-bands. Since most myofibrils were observed in a contracted state, H-bands and M-lines were not apparent.

The myofibrils lying in adjacent muscle cells made three types of mutual contacts : (1) end-to-end, (2) side-to-side, and (3) side-to-end. The end-to-end contacts were seen at the apposed plasma membranes of muscle cells, where the regions of cellular apposition were transverse to the myofibrillar axis (Fig. 4 and Text-fig. A). Such regions corresponded to the interfibrillar junctions of the intercalated disc. The side-to-side contacts were seen at 

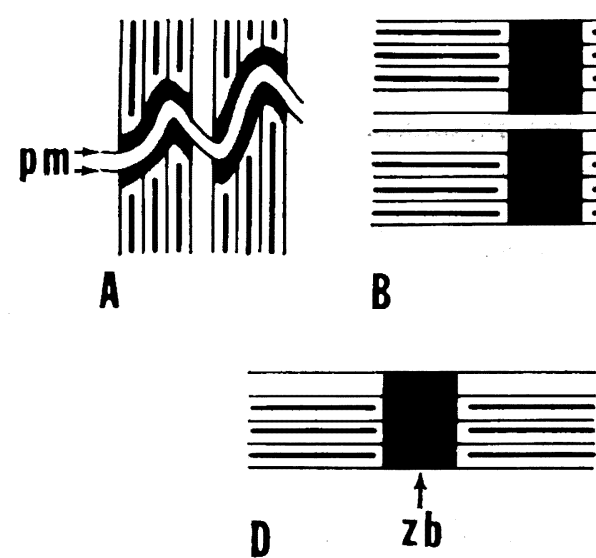

B
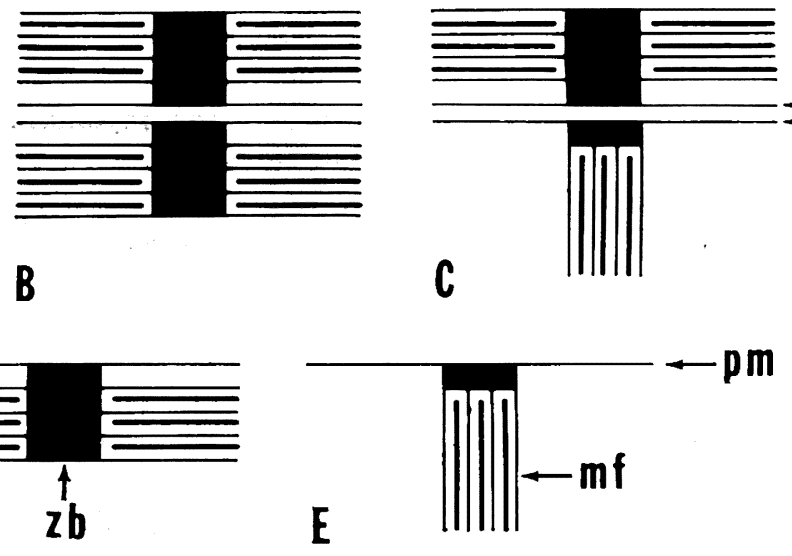

Text-fig. 1. Schematic drawings illustrating three types of contacts between myofibrils (A-C) and two types of attachments of a myofibril to the plasma membrane of the muscle cell (D and E), as observed in snail auricular muscle cells. (A) End-to-end contact corresponding to the interfibrillar junction of the intercalated disc; (B) side-to-side contact; (C) side-to-end contact; (D) attachment plaque; (E) hemidesmosome. mf: Myofibril, pm: plasma membrane of the muscle cell, $z b: Z$-body.

the apposed plasma membranes of adjacent cells, where the myofibrils within the two cells ran parallel with each other (Fig. 2 and Text-fig. B). The side-to-end contacts were found at the region of cellular abutment, where the myofibrils lying in both cells were arranged at an angle to each other (Fig. 7 and Text-fig. C). Intercalated discs were frequently observed (Figs. 2 and 4). The discs consisted of interfibrillar junctions, desmosomes, nexal areas, and unspecialized areas, and always occurred at the level of the Z-region. The area of interfibrillar junction appeared very narrow, probably due to the small size of the myofibrils. In addition, myofibrils were attached to the plasma membrane of the muscle cell in two ways, i.e., an attachment plaque and hemidesmosome. They were often found scattered over the whole plasma membranes (Figs. 2,3,4 and 7 and Textfigs. D and E).

The sarcotubular system in the snail auricular muscle cells was found running throughout the sarcoplasm. It was best seen along the plasma membrane, where it had a specialized area of contact (coupling) with the plasma membrane (Figs. 3, 4, 5 and 7). The network of the sarcotubular system was also seen surrounding each myofibril (Figs. 5 and 9). Tubule profiles associated with the Z-body could not be seen in these specimens.

Small nerve cords consisting of typical axons of various diameters, surrounded by cellular expansions of sheath cells, were widely distributed among the auricular muscle cells. The sheath cells appeared to correspond to those identified in gastropods by Nicaise (1967) as belonging to glial cells. They were easily recognizable by their large membranebounded inclusions having an amorphous dense content and attaining diameters of from 0.9 to $1.0 \mu \mathrm{m}$ (Figs. 3, 7, 8 and 10). Axons forming synapses on the muscle cells were often observed (e.g., Fig. 10). The axon membrane and muscle plasma membrane were separated from each other by a synaptic cleft 28 to 
$30 \mathrm{~nm}$ wide, which contained amorphous material. This material was connected with that of the basement membrane investing the muscle cell and axon. The pre- and post-synaptic membranes seemed very smooth in appearance and lacked any specialized regions throughout the length of the apposition. The pre-synaptic component contained a few mitochondria, some endoplasmic reticulum, numerous neurotubules, and the synaptic vesicles. Two types of vesicles were distinguishable according to their size and content: (1) small agranular vesicles with a mean diameter of $62 \mathrm{~nm}$, which were clustered against the pre-synaptic membrane, and (2) large granulated vesicles with a mean diameter of $158 \mathrm{~nm}$, which were scattered throughout the axoplasm. Both of them were usually found in the same axon, but the small ones were largely confined to the region near the presynaptic membrane.

\section{Discussion}

In the present study, the auricular muscle cells of the snail were shown to be more or less spheroidal structures, being gathered and abutting on each other with little extracellular space.

Fine structural investigations of cardiac muscle cells in the phylum Mollusca have been carried out on animals belonging to three main classes, i. e., Gastropoda (five species of pulmonates), Pelecypoda (three species of lamellibranchs), and Cephalopoda (three species of decapods). Plesch (1977), studying the ventricular muscle cells of the pond snail Lymnaea stagnalis (subclass Pulmonata, order Basommatophora), described cross-striated muscles consisting of short myofilaments (about $0.8 \mu \mathrm{m}$ ) and a large volume of sarcoplasmic reticulum and mitochondria. $\mathrm{He}$ noted that the myofibrils of the Lymnaea ventricle were composed of rows of Z-bodies arranged at right angles to the long axis of the cell, and that there were about nine thin filaments per thick filament. In the auricular and ventricular muscles of the agate snail Achatina fulica and closely related species Archachatina marginata (subclass Pulmonata, order Stylommatophora), a striated pattern has been observed, but the degree of symmetry was found to vary with the state of contraction (Baxter and Nisbet, 1963; Nisbet and Plummer, 1966, 1968, 1969). In these species, the ratio of thin to thick filaments was estimated to be $6: 1$, and the relation of the sarcotubules to the $Z$-bodies, to the mitochondria, to the sarcolemma and to the sarcolemmal invaginations was shown to be similar to those in many other muscle fibers of both vertebrates and invertebrates. Kawaguti (1963b), working with the land snail Euhadra hickonis (the same group as an agate snail), showed that the myofibrils were composed of parallel arrays of thick and thin myofilaments and an alternate arrangement of Z-membranes, the latter being represented by an irregular arrangement of dark granular bodies. He noted that the nucleus of the ventricular muscle cell was located centrally, while that of the auricular muscle cell lay peripherally. Intercalated discs were also shown by him to exist in both types of myocardial cells, but were not dealt with in any detail. Thus, it is difficult to compare the organization of such a structure in E. hickonis with that in the present specimens.

The ventricular muscle cells of the garden snail Helix aspersa (the same group as an agate snail) have been found by North (1963) to comprise myofibrils with a basic organization and well represented sarcotubular system. The Zband material of Helix is, however, of a fragmentary nature, and when these frag. ments are not lined up transversely the 
typical cross-striated nature of the fiber is not apparent. Although the pulmonate cardiac muscles referred to above reveal a fairly close structural similarity to those of the present material, little is yet known about the attachment of the myofibrils to the plasma membrane or the contact between muscle cells.

The ventricular muscle cells of the quahog Venus mercenaria (subclass Lamellibranchia, order Heterodonta) have been found to be equipped with dense bodies and attachment plaques (Hayes and Kelly, 1969; Kelly and Hayes, 1969), but no specialized attachments between abutting muscle cells such as intercalated discs have been detected. Such hearts are constructed from smooth muscle fibers, containing a central nucleus, glycogen, mitochondria, and paramyosin, much like the ventricles of the freshwater mussels Elliptio complanatus (Rutherford, 1972) and Unio douglasiae nipponensis (Kawaguti, 1963c) (the same group as a quahog).

Cephalopod hearts have been investigated by Kawaguti (1963a) in the cuttlefish Sepia esculenta, by Schipp and Schäfer (1969) in Sepia officinalis and by Jensen and Tj $\phi$ nneland (1977) in the related form Rossia macrosoma. These hearts have a highly differentiated organization. Although the Z-bodies of the cephalopod cardiac muscle are composed of fragmentary and discontinuous material, they appear similar in arrangement to those of the skeletal muscle and vertebrate cardiac muscle. Nevertheless, basic structures such as attachment plaques and dense bodies are still to be found.

In the present study, the myofibrils within the same cell were shown to run in various directions and to make frequent attachments to the plasma membrane in such ways as attachment plaques or hemidesmosomes. The individual myofibrils were, however, composed of only several thick filaments, so that the myofibrils lying in adjacent muscle cells often made various types of contacts, i. e., endto-end, side-to-side, and even side-to-end contacts. Such interfibrillar contacts are present between the cardiac muscle cells of the cuttlefish (Rossia): However, the intercalated disc appears to be better developed in Rossia, which seems to possess an interfibrillar junction of more distinct zigzag form, as seen in some crustaceans and vertebrates. Lamellibranch hearts still retain the nature of smooth muscle fibers and lack intercalated discs. Thus, it seems likely that the organization of molluscan cardiac muscles shows a progressive specialization, in which the dense bodies lying in lamellibranchs become transversely aligned and the contractile units come to lie in parallel with one another, giving rise to the basic constitution seen in the myofibrils of pulmonate hearts. The cephalopod hearts may represent the terminal development in such specialization.

Finally, with regard to the synaptic vesicles, some variations have been demonstrated. In the perioesophagic ganglia of the slug Vaginula solea, and snails Cryptomphallus aspersa and Helix pomatia, Gerschenfeld (1963) observed three types of vesicles: clear synaptic vesicles (60$80 \mathrm{~nm}$ in diameter), dense synaptic vesicles $(80-110 \mathrm{~nm})$, and neurosecretory vesicles $(120-140 \mathrm{~nm})$. In the optic tentacle retractor muscles of the snail Helix aspersa and slug Limax flavus, Rogers (1968) found small vesicles and large granulated ones, measuring about $50 \mathrm{~nm}$ and 80 $100 \mathrm{~nm}$ in diameter, respectively. In the posterior tentacles of the Argentine slug Vaginula soleiformis, Barrantes (1970) described a synaptic vesicle population consisting of clear synaptic vesicles $62 \mathrm{~nm}$ in diameter, and small and large intermediate granulated vesicles with diameters of $85.5 \mathrm{~nm}$ and $100-155 \mathrm{~nm}$. More recently 
in the buccal mass retractor muscles of the cephalaspid opisthobranch Philine aperta, three types of vesicles have been identified by Dorsett and Roberts (1980): clear vesicles (about $52 \mathrm{~nm}$ in diameter), cored vesicles of intermediate density $(120 \mathrm{~nm}$ in diameter), and cored vesicles of high density ( $120 \mathrm{~nm}$ in diameter).

The small clear vesicles found in these molluscan axons appear to correspond to the small agranular vesicles identified in the present study. They are the most commonly occurring variety of vesicles in the neuromuscular junctions of both vertebrates and invertebrates. The large granulated vesicles in the present material can be compared to those described by Gerschenfeld (1963) and Barrantes (1970). Since such vesicles are usually found near the pre-synaptic membrane, it is difflcult to qualify them as neurosecretory.

\section{Acknowledgements}

The author is grateful to Prof. R. Honjin, Department of Anatomy, and to Prof. T. Nakamura, Neuro-Information Research Institute, Kanazawa University School of Medicine, for making available thefacilities of their respective laboratories.

\section{References}

1) Barrantes, F.J.: The neuromuscular junctions of a pulmonate mollusc. I. Ultrastructural study. Z. Zellforsch., 104 : 205-212, 1970.

2) Baxter, M.I. and Nisbet, R.H.: Features of the nervous system and heart of Archachatina. revealed by the electron microscope and by electrophysiological recording. Proc. malac. Soc. Lond., 35 : 167-177, 1963.

3) Dorsett, D.A. and Roberts, J.B.: A transverse tubular system and neuromuscular junctions in a molluscan unstriated muscle. Cell Tissue Res., 206 :
251-260, 1980.

4) Gerschenfeld, H. M.: Observations on the ultrastructure of synapses in some pulmonate molluscs. Z. Zellforsch., 60 : 258-275, 1963.

5) Hayes, R.L. and Kelly, R.E.: Dense bodies of the contractile system of cardiac muscle in Venus mercenaria. J. Morph., 127 : 151-162, 1969.

6) Jensen, H. and Tjønneland, A.: Ultrastructure of the heart muscle cells of the cuttlefish Rossia macrosoma (Delle Chiaje) (Mollusca: Cephalopoda). Cell Tissue Res., 185: 147-158, 1977.

7) Kawaguti, S.: Electron microscopy on the heart muscle of the cuttlefish. Biol. J. Okayama Univ., 9: 27-40, 1963a.

8) Kawaguti, S.: Electron microscopy on the heart muscle of a snail. Biol. J. Okayama Univ., 9: 140-148, 1963b.

9) Kawaguti, S.: Electron microscopy on the heart muscle of a freshwater bivalve, Unio douglasiae nipponensis. Biol. J. Okayama Univ., 9: 149-155, 1963c.

10) Kelly, R.E. and Hayes, R.L.: The ultrastructure of smooth cardiac muscle in the clam, Venus mercenaria. J. Morph., 127: 163-176, 1969.

11) Midsukami, M.: Physiological salines. The formulae for animals from Protozoa to Vertebrata. Keigaku Publ. Co., Tokyo, pp. 40-52, 1979.

12) Midsukami, M.: The structure and distribution of satellite cells of cardiac muscles in decapod crustaceans. Cell Tissue Res., 219: 69-83, 1981.

13) Nicaise, G.: Description d'un $\gg$ système glio-interstitiel « chez Glossodoris (Gastéropode Opistobranche). C.R. Acad. Sci. (Paris), 264 : 2793-2795, 1967.

14) Nisbet, R.H. and Plummer, J.M. : Further studies on the fine structure of the heart of Achatinidae. Proc. malac. Soc. Lond., 37 : 199-208, 1966.

15) Nisbet, R.H. and Plummer, J.M.: The fine structure of cardiac and other molluscan muscle. Symp. zool. Soc. Lond., 22 : 193-211, 1968.

16) Nisbet, R.H. and Plummer, J.M. : Functional correlates of fine structure in the heart of Achatinidae. Experientia, 
suppl. 15: 47-68, 1969.

17) North, R.J.: The fine structure of the myofibers in the heart of the snail Helix aspersa. J. Ultrastruct. Res., 8 : 206-218, 1963.

18) Plesch, B.: An ultrastructural study of the musculature of the pond snail Lymnaea stagnalis (L.). Cell Tissue Res., 180 : 317-340, 1977.

19) Rogers, D.C.: Fine structure of smooth muscle and neuromuscular junctions in the optic tentacles of Helix aspersa and
Limax flavus. Z. Zellforsch., 89: 80-94, 1968.

20) Rutherford, J.G.: The structure of the ventricle of Elliptio complanatus, a fresh-water lamellibranch. J. Morph., 136: 421-432, 1972.

21) Schipp, R. and Schäfer, A.: Vergleichende elektronenmikroskopische Untersuchungen an den zentralen Herzorganen von Cephalopoden (Sepia officinalis). Die Feinstruktur des Herzens. $Z$. Zellforsch., 98 : 576-598, 1969. 


\section{PLATES}




\section{Explanation of Figures}

\section{Plate I}

All numbers above bars represent $\mu \mathrm{m}$.

Fig. 1. Section through the epicardium (E), connective tissue layer (C), and myocardium (M). $\mathrm{BM}$ : Basement membrane, PC: pericardial cavity. $\times 6,300$.

Fig. 2. Cross-section through three cardiac muscle cells showing the intercalated disc. The myofilaments in the same muscle cell are arranged disorderly, so that the disc consists of various components. The Golgi complex (thick arrow) is seen near the nucleus. A: Aband region, $\mathrm{AP}$ : attachment plaque, $\mathrm{CL}$ : cardiac lumen, $\mathrm{HD}$ : hemidesmosome, I: I-band region, MB: multivesicular body, NX: nexus, ssc: side-to-side contact of myofibrils lying in apposed muscle cells. $\times 12,000$. 
Plate I
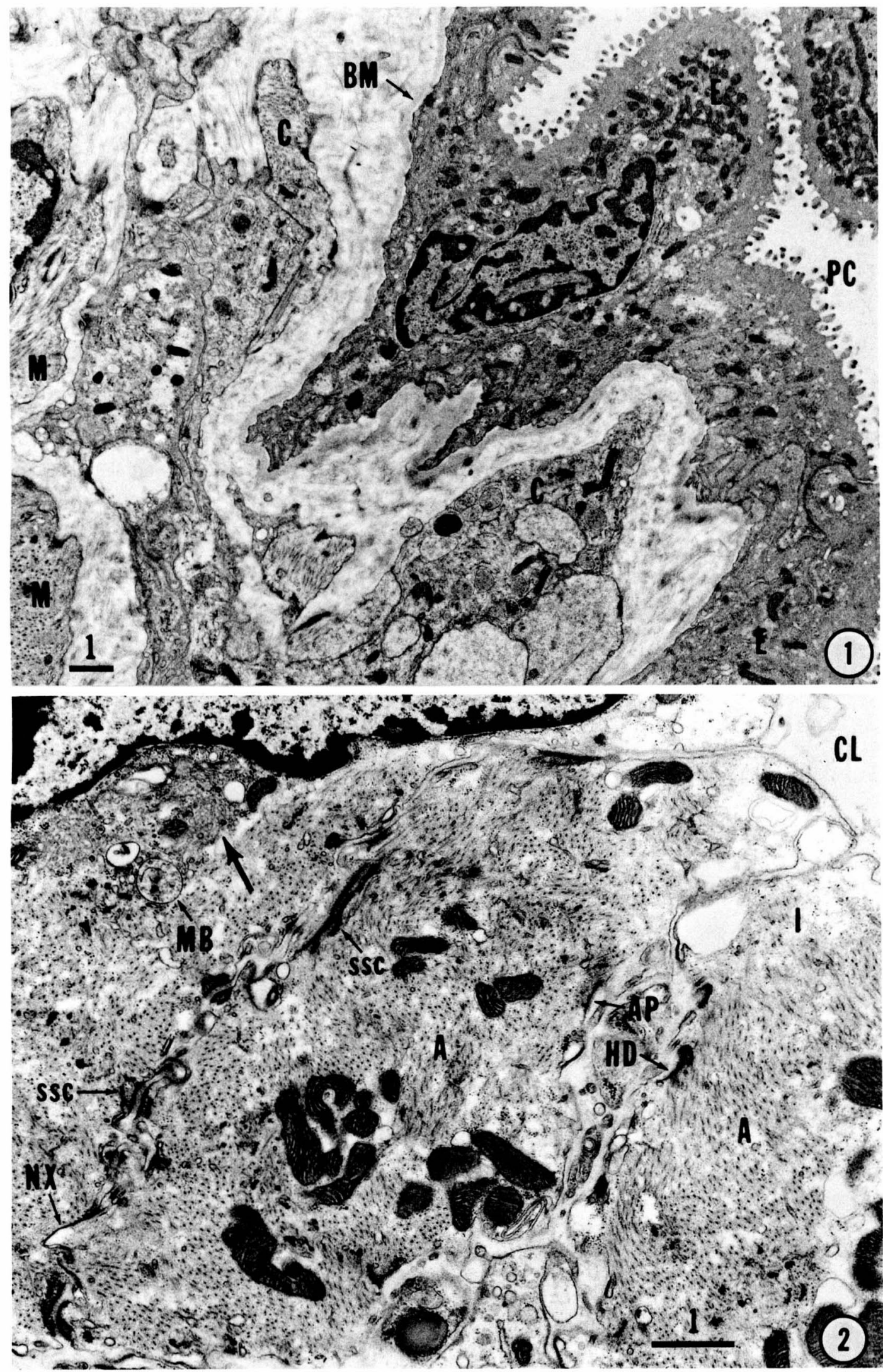

M. Midsukami 


\section{Plate II}

Fig. 3. Cross-section through cardiac muscle cells. Axons including numerous vesicles and the synapse are seen. Note the mitochondria forming dense aggregations in the central area of the muscle cell. Arrows indicate attachment plaque areas. Arrowheads show many couplings between the plasma membrane and sarcotubular system. GL: Glial cell. $\times 11,000$. 


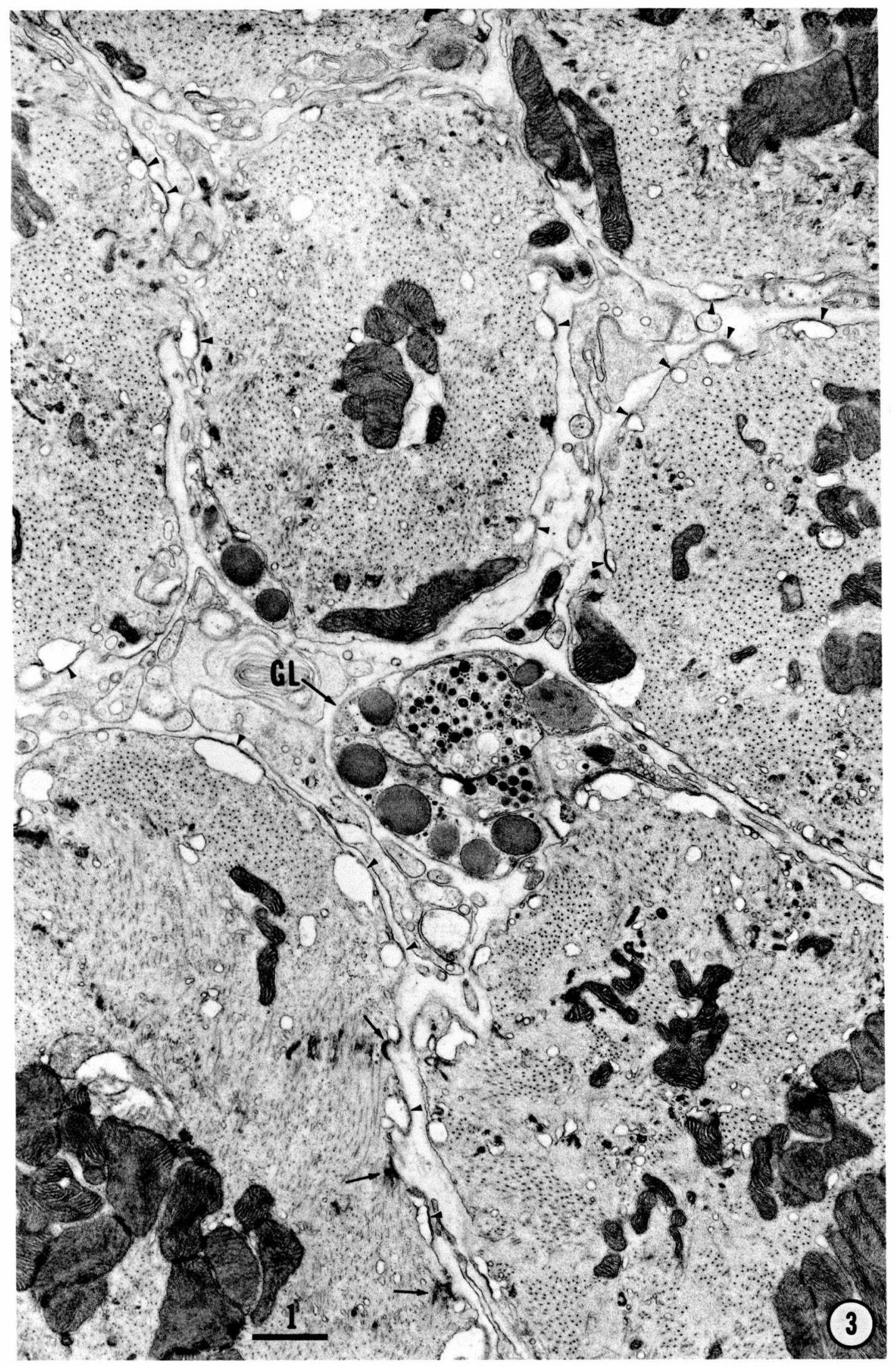

M. Midsukami 


\section{Plate III}

Fig. 4. Section through four cardiac muscle cells showing the intercalated disc (ID). Note the various arrangements of myofibrils. AP: Attachment plaque, HD: hemidesmosome. $\times 13,800$.

Fig. 5. Section of cardiac muscle cells showing the well-developed sarcotubular system around the Z-bodies (arrows). C: Coupling between the plasma membrane and sarcotubular system. $\times 15,700$. 
Plate III

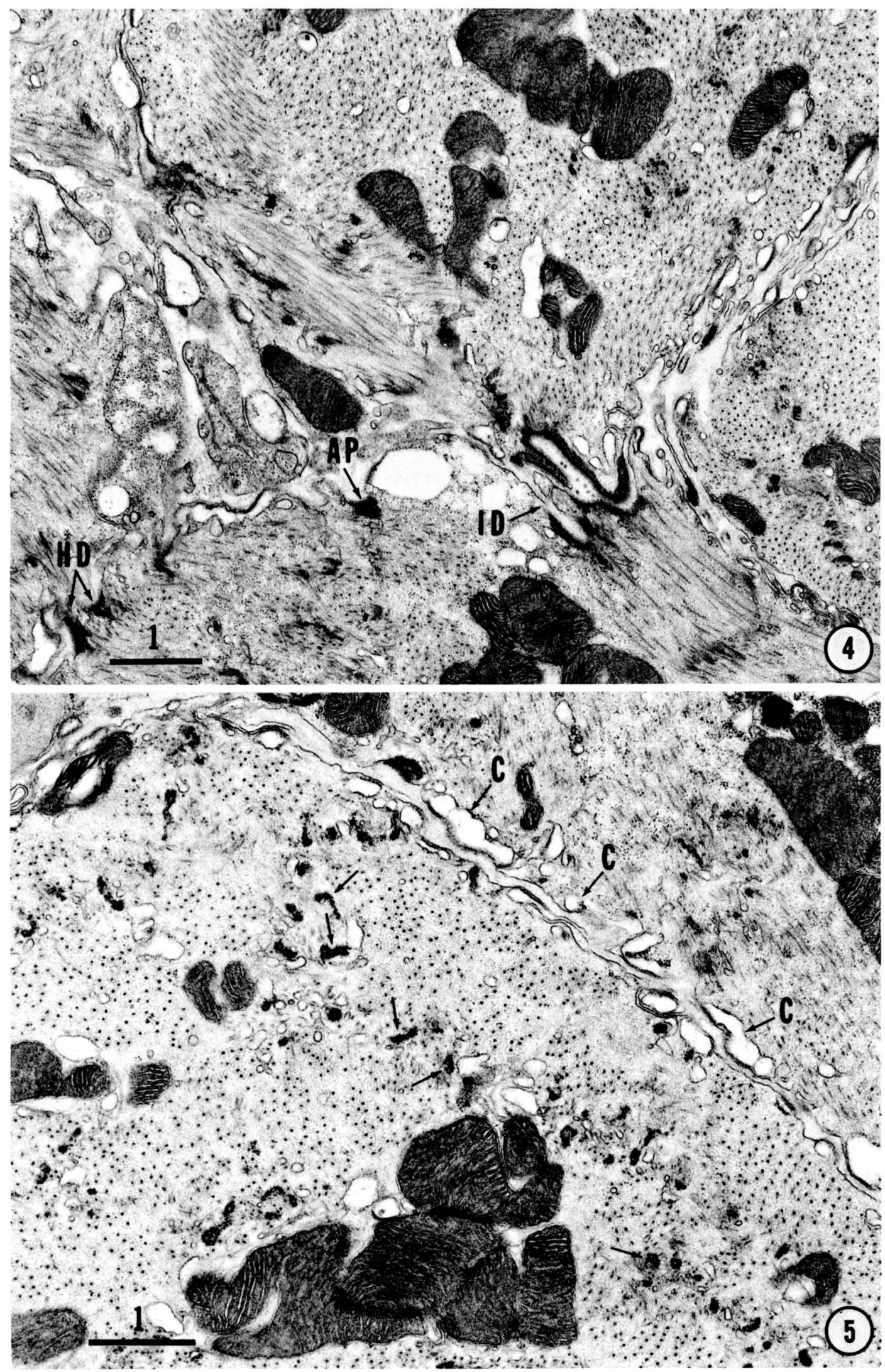

M. Midsukami 


\section{Plate IV}

Fig. 6. Cross-section of myofilaments showing the distribution of thick and thin filaments. A: A-band region, I: I-band region, ZB: Z-body. $\times 50,000$.

Fig. 7. Section through cardiac muscle cells and axons. Attachment plaques (thick arrows) and longitudinal tubules (thin arrows) are seen. Axons including large granulated vesicles and small agranular vesicles are enclosed by a glial cell, which also includes large, membrane-bounded bodies with a dense content. AX: Axon, BM: basement membrane, C : coupling, GL : glial cell. $\times 13,800$. 


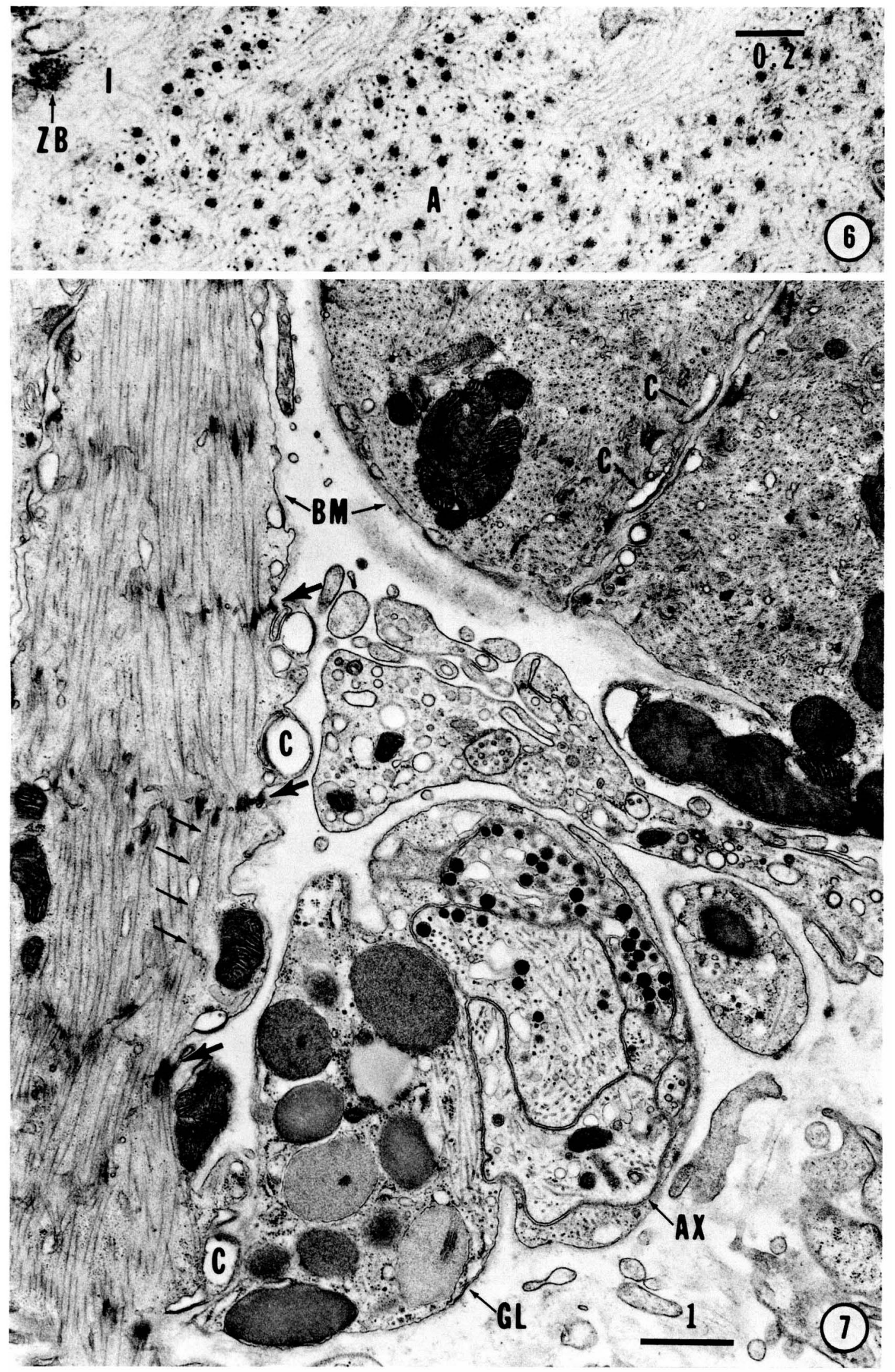

M. Midsukami 


\section{Plate V}

Fig. 8. Section through cardiac muscle cells showing an axon with numerous large granulated vesicles. C: Coupling. $\times 9,600$.

Fig. 9. Cross-section of cardiac muscle cell showing the abundant well-developed sarcotubular system (SR). A: A-band region, I: I-band region. $\times 20,000$.

Fig. 10. Magnified view of the axons shown in Fig. 3, indicating in more detail the axoplasmic components and the synapse (arrows). C: Coupling, GL: glial cell. $\times 24,000$. 
Plate V

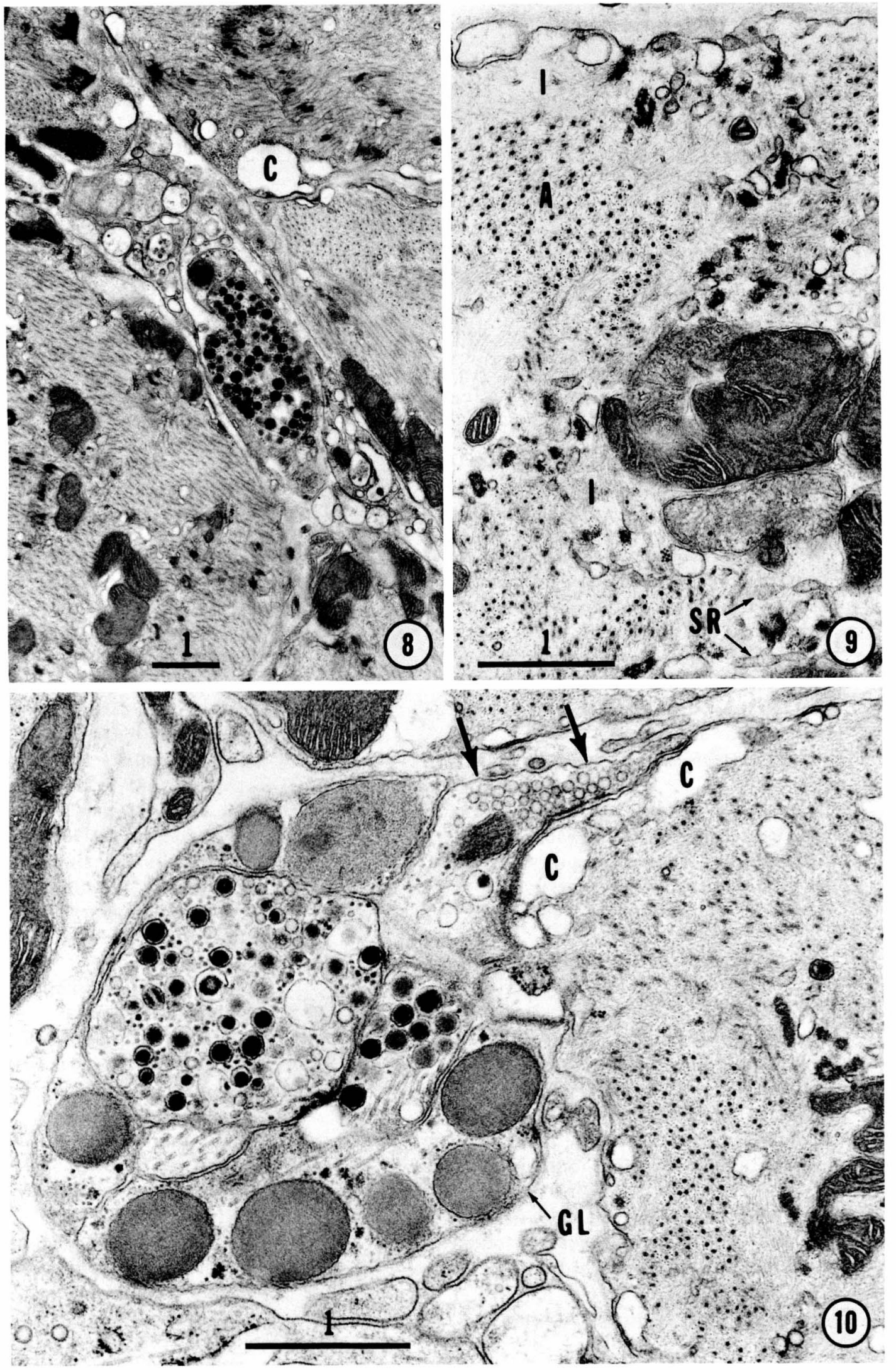

M. Midsukami 